dächtige Personen aber nicht freilassen wollte, wurden sie häufig erst gar nicht vor Gericht gestellt, sondern wegen eines minderen politischen Delikts angezeigt und einem Verwaltungsstrafverfahren unterzogen. Die Behörde umging damit das gerichtliche Verfahren mit öffentlicher Verteidigung und freier Beweisabwägung und konnte auf diese Weise Regierungsfeinde für einige Zeit festsetzen. Die in anderen Fällen so peinlich beachteten Grundsätze moderner Rechtsstaatlichkeit wurden im Interesse der Bekämpfung österreichfeindlicher politischer Aktivitäten ohne Skrupel umgangen, was wesentlich zum negativen Image der österreichischen Verwaltung in Oberitalien beitrug.

\title{
5. Militärdienstverweigerung
}

\section{Rekrutierungsflucht}

Die Militärdienstverweigerung stellte die österreichische Verwaltung in Venetien vor große Probleme. Ihre Ursachen waren vielfältig. Pazifistische Motive, die Unannehmlichkeit des langen Militärdienstes, aber auch der Widerwille in der österreichischen Armee zu dienen - verstärkt durch eine anti-österreichische Propaganda - sind die wichtigsten. Nach dem verlorenen Krieg von 1859 wurden daher in Wien große Zweifel an der Einsatzbereitschaft der österreichisch-italienischen Regimenter gehegt. Es schien wenig sinnvoll, Soldaten zum Militärdienst zu zwingen, auf die man sich im Ernstfall nicht verlassen konnte. Aus der Überlegung, daß die Regimenter mit Soldaten aus Venetien ,nur eine kostspielige Last und selbst eine Quelle von Verlegenheiten“"wären und die Wehrkraft der Monarchie schwächten, stellte Kaiser Franz Joseph eine teilweise Reduktion der italienischen Truppen, unter gleichzeitiger Einführung einer finanziellen Kompensation, zur Diskussion $^{437}$. Die Meinungen dazu waren geteilt. Finanzminister Bruck war dafür, während Innenminister Gołuchowski eine Sondersteuer ablehnte, sich dagegen Erleichterungen für das Loskaufen vom Militärdienst vorstellen konnte. Der Polizeiminister wies ,, auf den schlimmen Eindruck hin, welchen es in den anderen Kronländern machen würde, wenn die venetianischen Provinzen sich von der Militärpflicht ganz loskaufen könnten“. Franz Joseph beauftragte die Minister, diese ,,in militärischer und politischer Beziehung sehr wichtige Maßregel“ gründlich zu überdenken, die Regierung faßte aber keinen Beschluß.

Die Begeisterung der Venetianer, in der österreichischen Armee zu dienen, war tatsächlich gering. Viele zogen es vor, sich der Rekrutierung durch die Flucht ins italienische Ausland zu entziehen, wo sie in die piemontesische

\footnotetext{
${ }^{437}$ MK v. 8. Dezember 1859/2, ÖMR IV/1, Nr. 73.
} 
Armee eintraten oder untertauchten. Die Behörden waren gegen diese Art des passiven Widerstandes machtlos. Die Militärdienstverweigerer kamen fast ausschließlich aus den Städten und größeren Orten. Die agrarische Landbevölkerung wurde daher von der Rekrutierung unverhältnismäßig stark getroffen und gegenüber den Städtern benachteiligt, weil die Rekrutierungsbezirke die Städte und ihr Umland umfaßten und die ländlichen Gebiete das Defizit, das sich bei den Städten ergab, durch Nachmänner ausgleichen mußten. Auch höhere Alterklassen mußten damit rechnen, wieder zur Rekrutierung herangezogen zu werden. In der Ministerkonferenz vom 11. Februar $1860^{438}$ berichtete der Vertreter des Armeekommandanten, daß bereits so viele Stellungspflichtige aus den Städten emigriert seien, daß die vom Heeresergänzungsgesetz vorgesehene Stellung von Nachmännern fast unmöglich werde, wenn man nicht die politisch gemäßigte und ruhige Landbevölkerung „über die Gebühr in Anspruch nehmen und sie für die Emigration der städtischen Rekrutierungspflichtigen, für die sie nichts konnten, bestrafen" wolle. Das Armeeoberkommando schlug daher vor, die Stadt- und Landbezirke voneinander zu trennen und als Kompensation in den Städten sieben Altersklassen für die Rekrutierung heranzuziehen. Während Innernminister Gołuchowski prinzipiell mit der Zuteilung eines größeren Rekrutenkontingents an die lombardo-venetianischen Städte einverstanden war, wies Ministerpräsident Rechberg auf die Ungerechtigkeit einer Maßnahme hin, durch die „den pflichtgetreu zurückgebliebenen Konskriptionspflichtigen der Städte eine größere Last" auferlegt werde, weil man auf die höheren Alterklassen zurückgreifen und auch verheiratete Familienväter zum Militär einziehen hätte müssen - „So leiden somit die Unschuldigen für die Schuldigen." Er trat deshalb für eine finanzielle Abgeltung ein.

In Anbetracht des hohen Ausmaßes der Rekrutierungsflucht - es fehlten etwa 1000 Rekruten jährlich - sollten zur Entlastung der Landgemeinden und der höheren Altersklassen keine Nachmänner einberufen, sondern die zuständigen Gemeinden zur Bezahlung der gesetzlichen Stellvertretertaxe von 1200 Gulden für jeden abwesenden Soldaten verhalten werden. Die Summe sollte nach Möglichkeit von der Familie des Abwesenden, im Falle der Uneinbringlichkeit - das heißt im Normalfall - von der für den Rekrutierungsflüchtling zuständigen Gemeinde bezahlt werden. Die Lokalverwaltung mit Statthalter Toggenburg an der Spitze lehnte diese Regelung ab, weil dadurch die schon von der Wirtschaftskrise schwer getroffenen Gemein-

${ }^{438}$ MK v. 11. Februar 1860/3, ÖMR IV/1, Nr. 111. In diesen Tagen wurden auch alle 1859 geflüchteten Stellungsflüchtlinge amnestiert, was als Ergänzung zur Amnestie vom November 1859 verstanden wurde: Vortrag Gołuchowskis v. 9. Februar 1860, Ah.E. v. 15. Februar 1860, HHStA, Kab.Kanzlei, KZ 466. 
den noch zusätzlich belastet wurden. Die Gemeinden hatten außerdem keine polizeilichen Kompetenzen, um die Emigration der Rekrutierungsflüchtlinge zu unterbinden, wenn sie nicht die Stellungspflichtigen ,innerhalb der Gemeinde geradezu konfinieren "wollten, was praktisch unmöglich war, weil viele Städter bei Straßen- und Wasserbauten sowie bei Feldarbeiten außerhalb des Gemeindegebiets beschäftigt waren. Diese Maßnahme, die „ganz den Charakter extremer Mittel" an sich trage und in rechtlicher Hinsicht sehr fragwürdig war, sei außerdem „,mit der besonderen Gehässigkeit verbunden [...], die an allen Maßregeln der Strenge haftet, welche statt die einzelnen Schuldigen zu treffen die Gesamtheit der Bevölkerung drücken.“ Bei dem „Zustand der Zerrüttung, in dem das Ökonomikum der Gemeinden darniederliegt", könne eine Haftung in einer „,so imponierenden Größe" nur den Widerstand gegen die österreichische Verwaltung provozieren. Es werde damit in der Bevölkerung das Gefühl hervorgerufen, einer Gefahr ausgeliefert zu sein, „gegen die es für den einzelnen keine Abwehr gibt“. Die Maßnahme würde der ausländischen Presse „neuen Stoff zu dem beliebten Thema" ungerechter Regierungsmaßnahmen in Venetien bieten. Toggenburg meinte außerdem, daß ,das Übel noch nicht eine solche Ausdehnung gewonnen" habe, um ein derart hartes Vorgehen zu rechtfertigen $^{439}$.

Toggenburgs Warnungen blieben in Wien ungehört. Den sich im Ausland aufhaltenden Stellungsflüchtlingen wurde zwar „unter Nachsicht der Strafen der $\S \S 44$ und 45 des Heeresergänzungsgesetzes " ${ }^{* 40}$ bis zum Mai 1860 eine Frist gewährt, in der sie straflos in ihre Heimat zurückkehren konnten, ab der nächsten Rekrutierung sollten aber die Gemeinden zur Verantwortung gezogen werden ${ }^{441}$. Damit begann ein zwei Jahre dauernder Konflikt zwischen dem Land und der Zentralregierung. Statthalter Toggenburg verlangte zumindest einige Verbesserungen ${ }^{42}$. Erstens sollten, um einen Lastenausgleich zu erreichen, nicht die einzelnen Gemeinden, sondern die einen Stellungsbezirk bildenden Gemeindeverbände die Taxe entrichten. Zweitens verlangte er eine genaue Festlegung, bis zu welchem Verwandtschaftsgrad die Angehörigen zur Bezahlung der Taxen herangezogen werden konnten. Drittens urgierte er für Venetien die Außerkraftsetzung der Nachmänner-Regelung des Heeresergänzungsgesetzes, damit nicht einerseits Stellvertretertaxen eingehoben und andererseits auch noch Ersatz-

\footnotetext{
439 Toggenburg an Gołuchowski v. 24. Februar 1860, ASV, PdL 473, XV/16/1. Beiliegend das Schreiben Toggenburgs an Degenfeld v. 23. Februar 1860 und die Anfrage Degenfelds v. 18. Februar 1860.

440 RGBl. Nr. 167/1858.

441 Gołuchowski an Toggenburg v. 3. März 1860, ASV, PdL 473, XV/16/1.

${ }_{442}$ Toggenburg (gez. Guicciardi) an Innenministerium v. 17. Mai 1860, ebd.
} 
männer rekrutiert würden. Viertens verlangte Toggenburg, daß die Bezahlung der Stellvertretertaxe durch die Gemeinde keinem Freikauf entsprechen dürfe, der Rekrutierungsflüchtling also nicht straffrei war ${ }^{443}$. Schließlich sollte die Einhebung der Taxen nicht durch die Militärbehörden, sondern durch die politischen Behörden erfolgen. Das Innenministerium stimmte bis auf den ersten Punkt zu: Nicht, wie von Toggenburg gefordert, der gesamte Bezirk, sondern die Heimatgemeinde des Stellungspflichtigen sollte die Straftaxe bezahlen. Es sollte ausschließlich das Familienoberhaupt herangezogen werden, nicht aber ein Vormund oder entferntere Verwandte. Der Taxerlag durch die Familie war gleichbedeutend mit einem Freikauf des Rekrutierungsflüchtlings, wenn hingegen die Gemeinde die Steuer entrichtete, so konnte der Rekrutierungsflüchtling, wenn er zurückkehrte, innerhalb der durch das Heeresergänzungsgesetz vorgeschriebenen Fristen wieder eingezogen werden, was einen Aufschub des Militärdienstes für den Letztgereihten zur Folge hatte ${ }^{44}$, wodurch eine Benachteiligung derer vermieden werden sollte, die sich der Rekrutierung nicht widersetzt hatten. Die Statthalterei wollte die Bevölkerung möglichst schonend auf die neue Regelung vorbereiten und lancierte im nichtoffiziellen Teil der „Gazzetta Uffiziale“ einen Artikel darüber. Da auch ausländische Blätter bereits von den Plänen der österreichischen Regierung berichtet hatten, war man besonders bemüht, die positiven Aspekte in den Vordergrund zu rücken, daß nämlich die höheren Altersklassen von der Rekrutierung ausgenommen würden und eine gerechte Lösung erreicht worden sei ${ }^{445}$.

Während in den Landbezirken, wo es nur wenige Stellungsflüchtlinge gab, die Ablieferung der Stellvertretertaxen ab Oktober 1860 fast reibungs-

443 „E chiaro che se il pagamento della tassa da parte del distretto liberasse i requisibili dagli obblighi di leva, i giovani e specialmente quelli posti in circostanza tali di non essere chiamati fruttuosamente a riposizione, proverebbero troppo bene il loro tornaconto a portarsi e trattenersi all'estero fino a leva ultimata; come vi troverebbero il loro tornaconto in generale tutti quei giovani anche di famiglia agiate i quali non avessero gli estremi per ottenere regolarmente col volontario pagamento della tassa la liberazione del servigio militare." Ebd.

444 Innenministerium an Statthalterei v. 19. Juni 1860, ebd.

445 „Per quanto possiamo rilevare da fonte competente, tale disposizione sussiste di fatto, ma non già ne' termini, ne' quali la si riportava, mentre dagli esteri periodici ne veniva mutilato il testo in modo, da impedire che se ne comprendesse il vero precipuo scopo, quello, cioè, della tutela de' giovani soggetti alla leva e rimasti tranquillamente a' loro focolari." Der namentlich nicht genannte Autor beruhigte, daß eine Publikation dieses Gesetzes derzeit noch nicht aktuell sei, weil die Rekrutierung für diesen Jahrgang ausgesetzt sei. „A prevenire sinistre impressioni“ wolle er in dem Artikel die wichtigsten Bestimmungen der geplanten Regelung zusammenfassen. Erschienen in der Gazzetta Uffiziale di Venezia v. 8. August 1860 . 
los erfolgte ${ }^{446}$, war in den Städten die Lage weitaus problematischer. So hätte etwa Venedig mit 150 Stellungsflüchtlingen 200.000 Gulden an Strafsteuern zu entrichten gehabt. Das überstieg die finanzielle Leistungsfähigkeit der Gemeinden (Toggenburg: „Non crederei che in questo momento potessi dai comuni neppur pensarsi o che si avesse la minima probabilità di riuscita"). Toggenburg warnte erneut, daß sich die Regierung unmöglich mache und Unruhe in der Bevölkerung provoziere. Er schlug eine gleichmäBige Aufteilung der Stellvertretertaxen auf alle Gemeinden und ihre gleichzeitige Stundung vor. Als Garantie sollten die noch immer nicht beglichenen Militärprästationen - also die Schulden, die die Militärverwaltung bei den Gemeinden hatte - dienen. Er befürchtete „una assai sinistra impressione“, wenn die Regierung eine „Strafsteuer“ einführte, obwohl die Ansprüche der Gemeinden an das Ärar seit Jahren nicht beglichen worden waren („devono per tanto tempo attendere le pratiche di liquidazione od il pareggio dei crediti proprii“").

In Wien wurde auf diese Vorschläge nicht reagiert. Für Lombardo-Venetien war für 1861 - der ersten Rekrutierung, bei der die neue Regelung galt - ein Kontingent von 6414 Personen vorgesehen. Die Supplentengebühr, die noch vor Beginn der Rekrutierung zu begleichen war, wurde mit 1200 Gulden festgesetzt ${ }^{447}$. Die Zentralkongregation protestierte in ihrer

446 Toggenburg (gez. Guicciardi) an Gołuchowski v. 3. Oktober 1860, ASV, PdL 473, XV/ 16/1. Toggenburg schrieb: „,Ma crederei però di mancare ad un preciso dovere, qualora fino da questo momento non richiamassi la superiore attenzione sulle circostanze le quali per alcuni comuni possono rendere ardua oltre modo, per non dire impossibile, la contemplata puntualità di pagamento."

447 Veröffentlicht am 26. September 1860 im Landesgesetzblatt 1860, Nr. 53 und Nr. 55; für 1862 wurde die Gebühr am 1. Jänner 1862 festgesetzt, siehe Landesgesetzblatt 1862, Nr. 1. Die Militärstellungsbezirke waren bereits am 20. März und am 1. April 1860, Nr. 23. und Nr. 24 festgelegt worden. Die Bestimmungen über Militärbefreiungen folgten mit Statthaltereierlässen v. 10. Oktober, Nr. 54, v. 22. Oktober, Nr. 59 (Studenten) und v. 25. Oktober 1860, Nr. 62 (Lehrer). Am 9. Februar 1861 wurden auch die besten Kunststudenten vom Militärdienst befreit, Landesgesetzblatt 1861, Nr. 12. 1862 wurden 6417 Mann rekrutiert (Landesgesetzblatt 1861, Bekanntmachung v. 21. Oktober 1861, Nr. 35). Die gleiche Zahl galt auch für 1863. Auch sonst wurden für die Rekrutierung 1863 die gleichen Bestimmungen wie in den Vorjahren angewandt: Landesgesetzblatt 1862, Nr. 28 und 30, Kundmachungen v. 18. und 23. Oktober 1862. Für 1864 wurden die Bestimmungen am 13. Oktober 1863, Landesgesetzblatt 1863, Nr. 23, bekanntgemacht. 1865 blieb die Zahl der Rekruten gleich, Landesgesetzblatt 1865, Kundmachung v. 13. Oktober 1864. 1866 wurden 6394 Mann rekrutiert, siehe Landesgesetzblatt 1865, Nr. 25; die Supplententaxen wurden auf 1000 fl. gesenkt: Kundmachung v. 20. November 1865, Nr. 28. Vor Kriegsausbruch kam es zu einer zweiten Rekrutierung: Kundmachung v. 23. Mai 1866, Landesgesetzblatt 1866, Nr. 18. Zu den Supplententaxen siehe Landesgesetzblatt 1860, Bekanntmachung der Statthalterei v. 28. Oktober $1860, \mathrm{Nr} .74$. 
Eigenschaft als Landesvertretung beim Staatsministerium, doch vergeb$\operatorname{lich}^{448}$. Um sich Klarheit zu verschaffen, beauftragte die Statthalterei die Delegationen mit einer Erhebung, wie hoch die zu erlegende Taxe in den einzelnen Provinzen ausfallen werde ${ }^{449}$. Die Delegaten waren sich einig, daß in Anbetracht der schlechten Wirtschaftslage nicht die geringste Chance bestand, daß die Supplententaxen jemals bezahlt werden würden. Der Delegat von Vicenza wies außerdem darauf hin, daß die meisten ihre Heimat nicht aus politischen Gründen oder um sich vom Militärdienst zu drücken, sondern aus wirtschaftlichen Erwägungen verlassen hatten. Die Rekrutierungsflüchtlinge kamen tatsächlich nicht aus der besitzenden Klasse, sondern aus dem Stand der Handwerker und der Gewerbetreibenden. In der Provinz Vicenza stammten nur vier der insgesamt 111 abwesenden Stellungspflichtigen aus der vermögenden Schicht, alle anderen kamen aus den Unterschichten. Die vier abgerechnet, bei denen die Taxe von den Familien bezahlt wurde, ergab sich damit für die Provinz Vicenza eine Summe von 128.400 Gulden ${ }^{450}$. Auch in den anderen Provinzen war die Lage ähnlich: In Padua waren etwa 10-15 Familien in der Lage, die Supplententaxen zu bezahlen ${ }^{451}$, in Treviso waren es 23 von $172^{452}$, in Verona knapp zehn von 88 Abwesenden $^{453}$. In der Provinz Belluno waren für 27 Personen Supplententaxen zu zahlen: 12 von Belluno, 13 von Feltre und zwei von Longarone ${ }^{454}$. Insgesamt mußten demnach in Venetien die Gemeinden für 918 illegal abwesende Stellungspflichtige aufkommen. Die Enttäuschung und das Entsetzen über diese Entscheidung der Regierung war sogar bei den österreichtreuen Austriacanti sehr groß. Eine Welle der Empörung und der Proteste war die Folge.

In Wien wurde dem und den Bedenken der Landesbehörden und -vertretungen kein Gehör geschenkt. Bereits in der Ministerkonferenz vom 15.

448 Eingabe der Zentralkongregation an das Staatsministerium v. 26. Oktober 1860, ASV, PdL $473, \mathrm{XV} / 16 / 1$.

${ }_{449}$ Schreiben der Statthalterei an die Delegaten mit Ausnahme von Rovigo und Vicenza v. 21. Februar 1861, ebd.

450 Siehe dazu ausführlich Andreas GotTsmann, Il Veneto tra riformismo austriaco e rivoluzione nazionale. La provincia di Vicenza negli anni sessanta, in: Alba LazZaretTo-Zanolo (Hg.), La "primavera liberale" nella terraferma veneta 1848 (Venezia 2000) 129-155, hier $145-148$.

${ }^{451}$ Bericht des Delegaten von Padua v. 12. März 1861, ASV, PdL 473, XV/16/1. Der Delegat berichtet nicht über die Gesamtzahl der Stellungsflüchtlinge.

${ }_{452}$ Bericht des Delegaten von Treviso v. 24. Februar 1861, ebd.

453 Bericht des Delegaten von Verona v. 25. Februar 1861, ebd.

454 Bericht des Delegaten von Belluno v. 26. Februar 1861, ebd. Auch er gibt keine Gesamtzahl der Stellungsflüchtlinge an. Es liegen keine Berichte aus Rovigo, Mantua und Udine vor. 
November 1860 wurde die von der Zentralkongregation beantragte und von Statthalter Toggenburg befürwortete Aussetzung der Rekrutierung für 1861 abgelehnt $t^{455}$, ebenso die Verminderung des lombardo-venetianischen Kontingents wie längere Zahlungsfristen und die Aufrechnung mit den Kriegsprästationen, letzteres, weil „die Liquidierung der Kriegsprästationsforderungen noch im Zuge ist, mithin von einer Kompensation dieser mit der obigen Schuldigkeit noch keine Rede sein kann". Gołuchowski beantragte in Übereinstimmung mit dem Tiroler Statthalter sogar die Ausweitung der Maßnahme auf das Trentino, ,, wo ganz gleiche Verhältnisse wie im lombardisch-venetianischen Königreich bestehen. "456 Die Gemeinden Venetiens wurden damit jährlich mit über einer Million Gulden zusätzlich belastet. Die Stadtverwaltung Venedigs kündigte deshalb die Entsendung einer Deputation nach Wien an, und Toggenburg empfahl dringend die Zurücknahme der Anordnungen. Doch die Regierung blieb hart:

„Der Staatsminister fände jedoch keinen hinlänglichen Grund zur Aufhebung dieser in der Konferenz wiederholt beratenen und angenommenen Maßregel, es wäre denn, daß der Kriegsminister jene 918 Mann für die Armee entbehrlich fände oder der Polizeiminister besondere Daten über einen Umschwung in der politischen Stimmung des Landes anzuführen vermöchte. “457

Da keines von beiden der Fall war, beschloß die Ministerkonferenz die Exekution der neuen Bestimmungen, ,,Minister von Lasser übrigens mit der Bemerkung, daß er, obwohl prinzipiell gegen jene Verordnung, doch gegenwärtig auf deren Vollzug einraten müsse, damit das Ansehen der Regierung nicht leide, wenn Strafen nur angedroht und nicht vollzogen werden."

Im März 1861 reiste die angekündigte Deputation der Gemeinde Venedig und der Zentralkongregation, bestehend aus dem Podestà Bembo und dem Zentraldeputierten Ferrari, ,zwei ehrenwerten, anständigen, intelligenten, von jeder systematischen Opposition gegen die kaiserliche Regierung sich fernhaltenden Männern“, nach Wien. Der Ministerrat empfahl ihren Empfang durch den Kaiser ${ }^{458}$, der am 7. März zustimmte ${ }^{459}$, nachdem Lasser betont hatte, daß es sich die Regierung und der Kaiser nicht leisten könnten, in einer so schwierigen Zeit eine Deputation der loyalen Landesvertretung zurückzuweisen. Auch eine teilweise Genehmigung ihrer Bitten werde,

${ }^{455}$ MK v. 15. November 1860/1, ÖMR IV/2, Nr. 228 sowie Vortrag Gołuchowskis v. 16. November 1860, HHStA, Kab.Kanzlei, KZ 3718, Ah.E. v. 16. November 1860.

${ }^{456}$ Zum Trentino siehe bereits MK v. 13. November 1860/1: ÖMR IV/2, Nr. 227. Die Ausdehnung auf den Trienter Kreis wurde genehmigt.

457 Gołuchowski in der MK v. 29. Dezember 1860/3, ÖMR IV/2, Nr. 254

458 MR v. 3. März 1861/3, ÖMR V/1, Nr. 22.

459 Ah.E. v. 7. März 1861 auf den Vortrag Lassers v. 4. März 1861, HHStA, Kab.Kanzlei, KZ 680 . 
so Lasser, wohl notwendig sein. Er selbst empfing die beiden Abgesandten in seiner Privatvilla in Dornbach und sagte ihnen zu, daß er sich für wesentliche Erleichterungen einsetzen werde ${ }^{460}$. Die Deputation war der vorläufige Höhepunkt der Diskussionen zwischen Wien und Venedig: Toggenburg hatte bereits am 28. Dezember 1860 telegrafisch den Beschluß des Gemeinderats von Venedig, Podestà Bembo mit einem Gesuch um Nachsicht der Straftaxen nach Wien zu senden, mitgeteilt. Gleichzeitig ersuchte er wieder um die Aufhebung der Maßnahme „aus Gründen der Billigkeit und der Politik“. Das war in der oben erwähnten Ministerkonferenz vom 29. Dezember abgelehnt worden, was Toggenburg am 30. Dezember telegrafisch mitgeteilt wurde. „Seither sind einzelne derlei Gesuche (von Padua und Ceneda) bei dem Staatsministerium eingelangt und in Verhandlung genommen, andere aber, und zwar in größerer Zahl, bei den verschiedenen Provinzialkongregationen angeregt und von diesen zur Kenntnis der Zentralkongregation gebracht worden." 461

Am 23. März stand die Angelegenheit nach der Vorsprache der venetianischen Delegation neuerlich auf der Tagesordnung des Ministerrates. Die Zahl der illegal abwesenden Militärpflichtigen, für die Taxen von den Gemeinden zu bezahlen waren, hatte sich mittlerweile auf 927 erhöht, insgesamt waren 1001 Personen abwesend. Nur $10 \%$ der Supplententaxen konnten von den betroffenen Familien erlegt werden. Die ausständigen 1,2 Millionen Gulden sollten von den Gemeinden in sechs Monatsraten bezahlt werden. Lasser empfahl einige Erleichterungen, die vom Ministerrat genehmigt wurden ${ }^{462}$. Er folgte dabei einer Anregung Toggenburgs, wie in anderen Kronländern die Bezahlung in Banknoten im Nennwert zu gestatten, was einer fast $50 \%$-igen Reduktion der Zahlungsverpflichtungen entsprach. Das sollte aber nur für Gemeinden gelten, nicht für Familien, ,weil sonst Reklamationen von jenen Familien zu besorgen [sind], welche schon in Silber gezahlt haben“. Angenommen wurde auch der Vorschlag des Statthalters, daß die Schulden zahlungsunfähiger Gemeinden teilweise oder vollständig vom Landesfonds übernommen werden sollten ${ }^{463}$. Den Antrag Toggenburgs, die Zahlungsfrist von sechs Monaten auf vier Jahre zu erstrecken, lehnte Lasser ab, ,weil schon im nächsten Jahre voraussichtlich neue diesfällige Zahlungen vorkommen werden, woraus sodann eine Häu-

\footnotetext{
${ }^{460}$ Bembo an Lasser v. 11. Juli 1862, ASV, PdL 597, XIII/3/2.

461 Die hier von Lasser angesprochenen Gesuche sind im AVA nicht erhalten.

${ }^{462}$ MR II v. 23. März 1861/2, ÖMR V/1, Nr. 37.

${ }_{463}$ Vortrag des Ministerpräsidenten Erzherzog Rainer v. 2. April 1861 über den Vortrag Ministers Ritter v. Lasser v. 28. März 1861, Ah.E. v. 3.4.1861, HHStA, Kab.Kanzlei, KZ 1029. Der Staatsrat stimmte dieser Maßnahme zu. Siehe dazu J. Staatsrat, Z 28/1860.
} 
fung der Jahresraten und neue Verwicklungen entstehen müßten“. Die venetianische Deputation konnte aber doch noch die Verlängerung der Zahlungsfrist auf zwei Jahre, bis zum Jahresende 1862, durchsetzen ${ }^{464}$.

Trotz dieser Erleichterungen stellte die Zahlung der Supplententaxen die Gemeinden vor große Schwierigkeiten. Ende des Jahres schrieb Toggenburg, es sei mehr als fraglich, „,wann und ob sie überhaupt jemals in den Staatsschatz einfließen werden“. Diese Maßnahme sei „fortwährend der Gegenstand der bittersten Kritik, indem die bezügliche Maßregel als eine ganz außerhalb des Gesetzes liegende beurteilt wird“. Die Bevölkerung habe kein Verständnis dafür: „Allein [wie] es angehen soll, die Grundlagen der Steuerpflicht und der Wehrpflicht nach bloßen Opportunitätsrücksichten zu verrücken, damit konnte sich die öffentliche Meinung nie befreunden." Toggenburg schlug vor, die Supplententaxenregelung anläßlich der geplanten Reise Franz Josephs nach Venedig, bei der Staat und Monarch einen möglichst positiven Eindruck vermitteln wollten, durch einen kaiserlichen Gnadenakt aufzuheben. Damit könne die Staatsverwaltung ihr Gesicht wahren und ein wenig rühmliches Kapitel österreichischer Verwaltung abschließen. Die von den Gemeinden bereits eingezahlten 72.000 Gulden sollten zurückerstattet werden ${ }^{455}$. Lasser lehnte das ab, weil „,in den Verhältnissen, welche [die Maßregel] hervorgerufen habe, keine entscheidende Änderung eingetreten sei. “466 Die Gemeinden hätten ausreichend Zeit gehabt, die Auswanderung zu unterbinden. Nun müßten sie die finanziellen Konsequenzen tragen ${ }^{467}$.

Anfang 1862 baten dann aber so viele Gemeinden um Erleichterungen, daß Lasser die Angelegenheit am 5. Juni neuerlich vor den Ministerrat bringen mußte. Toggenburg hatte als Kompromiß vorgeschlagen, die vermutlich Untauglichen von der Gesamtsumme der Stellungspflichtigen abzuziehen, Maßstab dafür sollten frühere Rekrutierungsergebnisse sein, wobei das Verhältnis der Untauglichen zu den Tauglichen in Venedig $1: 2$,

${ }^{464}$ MR v. 9. April 1861/3, ÖMR V/1, Nr. 45 sowie Ah.E. v. 17. April 1861 auf den Vortrag Lassers v. 14. April 1861, HHStA, Kab.Kanzlei, KZ 1175. Die Einzahlung der Supplententaxen wurde durch einen Statthaltereierlaß v. 3. Juni 1861 geregelt. Siehe Landesgesetzblatt 1861, Nr. 44

${ }_{465}$ Statthalterei an Staatsministerium v. 6. November 1861, ASV, PdL 473, XV/16/1.

${ }_{466}$ MR II v. 30. November $1861 / 5$, ÖMR V/3, Nr. 161

${ }^{467}$ Vortrag Lassers v. 3. Dezember 1861, Genehmigung des Antrags mit Ah.E. v. 19. Dezember 1861, HHStA, Kab.Kanzlei, KZ 3857. Mit der Kundmachung v. 29. Oktober 1861 war festgelegt worden, daß nach der Ah.E. v. 21. Oktober 1861 für die Rekrutierung 1862 die gleichen Grundsätze gelten sollten wie im Jahre 1861: Landesgesetzblatt 1861, Nr. 39. Zur Frage der ungerechtfertigten Einziehung von Nachmännern in Zusammenhang mit der Rekrutierungsflucht siehe Vortrag Lassers v. 6. Februar 1862, Ah.E. v. 8. Februar 1862, HHStA, J. Staatsrat, Z 765/1861. 
außerhalb Venedigs $5: 8$ betragen hatte, was praktisch einer Halbierung der Stellungstaxen bedeutet hätte ${ }^{468}$. Die verbleibende Summe sollte in Papiergeld entrichtet und auf drei Jahre gestundet werden. Lasser war trotz der ablehnenden Haltung des Kriegsministers damit einverstanden und wies darauf hin, daß die Stellvertretertaxe

„eigentlich nicht im Gesetze begründet ist und nur durch die in Italien obwaltenden außerordentlichen Verhältnisse gerechtfertigt werden kann und andererseits die italienischen Gemeinden seit drei Jahren für die Militärbequartierung fortwährend empfindliche Opfer bringen müssen, sodaß Schonung angezeigt sei, um sie nicht völlig zu ruinieren." 469

Obwohl dadurch die Maßnahme weitgehend aufgeweicht war, lehnte er eine gänzliche Rücknahme der Verordnung ab, ,da dies ein Bekenntnis der Ungerechtigkeit ihrer Auflegung" wäre. In der Regierung zeigte sich auch in dieser Frage die prinzipielle Meinungsdifferenz, die sich quer durch alle Behörden zog: Eine starke Minderheit wollte alle finanziellen Belastungen, die Österreich direkt oder indirekt aus der italienischen Frage erwuchsen, auf das Kronland Lombardo-Venetien als dem vermeintlich Hauptschuldigen abwälzen:

„Der Geist der italienischen Bevölkerung bedarf solcher Maßregeln, und schon die Franzosen hatten vor Jahren die Kommunen für die in ihrem Weichbild begangenen Räubereien verantwortlich erklärt - und zwar mit Erfolg. Wenn heuer die Zahl der Flüchtlinge gestiegen ist, so geschah es eben, weil man nicht an den Ernst der Regierung glaubte. ${ }^{470}$

Letztlich setzte sich dann aber doch fast in allen Fällen die moderate Mehrheit durch. Vor allem Schmerling pochte auf eine Gleichbehandlung Venetiens und war sich in diesem Punkt mit Toggenburg zumindest prinzipiell einig. Er unterstützte auch in der Frage der Supplententaxen den gemäßigten Lasser gegen die Wünsche des Militärs. Um das Gesicht zu wahren, sollten weitgehende Erleichterungen eintreten, vor einer endgültigen Aufhebung schreckte die Regierung aber immer noch zurück ${ }^{471}$. Auch gegen die von Toggenburg vorgeschlagene gänzliche Nachsicht der bisher aufgelaufenen Schulden sprach sich Lasser aus: „Würden die Gemeinden für das Jahr 1861 von der Taxzahlung enthoben, so könnten sie weder für

${ }^{468}$ Es wurden dann etwa zwei Fünftel als Untauglich angenommen und von den Taxen abgezogen.

${ }^{469}$ Stellungnahme Lassers im MR v. 5. Juni 1862/1, ÖMR V/2, Nr. 236.

470 Übrigens sprachen sich auch die Ungarn Nádasdy und Esterházy gegen die von Lasser beantragten Erleichterungen aus.

${ }^{471}$ Vortrag Lassers v. 10. Juni 1862, Ah.E. v. 16. Juni 1862, HHStA, Kab.Kanzlei, KZ 1743 . 
das Jahr 1862 noch weiterhin hiezu verhalten werden." Die Folge wäre, daß man die Maßnahme auch für die Familien, die die Stellvertretertaxen erlegen konnten, aufgeben müßte, „denn es ist klar, daß falls die Maßregel, selbst wenn ihre Ungesetzlichkeit nicht ausdrücklich zugegeben würde, zu 9/10 aufgegeben wäre, das letzte Zehntel sich nicht mehr halten ließe“.

Lasser legte die endgültige Abrechnung für die Rekrutierung 1861 vor: Demnach waren 991 Stellungspflichtige abwesend, aber nur 86 Familien zahlungsfähig, was bedeutete, daß auf die Gemeinden 1,080.000 Gulden entfielen. Durch die Heeresergänzung 1862 kam eine weitere Million hinzu, die Gesamtschuld Venetiens an Stellvertretertaxen belief sich damit bereits auf über 2 Millionen. Gleichzeitig hatte der Landesfonds für die Militäreinquartierung seit 1859 etwa 3 Millionen Gulden aufzubringen gehabt „und dies zu einer Zeit, wo der Wohlstand der Bevölkerung durch die Traubenkrankheit, dann die Krankheit der Seidenwürmer, endlich durch die Trockenheit des vorigen Jahres untergraben ist". Da eine Einigung im Ministerrat nicht möglich war, legte Lasser dem Kaiser zwei alternative Resolutionsentwürfe vor, einen, der die von ihm unterstützten Erleichterungen genehmigte - er wurde auch von Erzherzog Rainer, dem Vorsitzenden des Ministerrats, unterstützt - und einen, der die Gesuche der Zentralkongregation und der Munizipalkongregation von Venedig ablehnte. Franz Joseph entschied sich für die gemäßigte Variante. Der Kampf gegen die Supplententaxen war damit aber nicht beendet, es hagelte weiterhin Proteste und Eingaben.

Für die Gegner der österreichischen Regierung in Venetien war diese Maßnahme ein willkommenes Argument in ihrer Propaganda für einen Anschluß des Landes an Italien. In Proklamationen wurden die Gemeinden aufgefordert, die Zahlung der Taxen für Konskriptionsflüchtlinge zu verweigern. Verbunden damit wurde eine allgemeine Anklage gegen die österreichische Verwaltung, ihre Fehler und ihre Unterlassungen. Auffallend ist die nur sehr wenig propagandistisch geprägte Sprache, die Fakten wurden in möglichst objektiver Weise dargestellt. In sprachlich-formaler Hinsicht unterschieden sich manche Flugschriften kaum von offiziellen Gesuchen an die Regierung und an den Kaiser, denn der Regierung selbst war es mit der Einführung der Supplententaxen gelungen, ihren Gegnern die besten Argumente zu liefern und sogar die „Gutgesinnten“ gegen sich aufzubringen. Die antiösterreichische Opposition prangerte insbesondere die Ungerechtigkeit an, daß die Gemeinden und der Besitz für die Emigration verantwortlich gemacht wurden, obwohl sie keinerlei Möglichkeit hatten, diese zu unterbinden. Nicht die Gemeinden wären Schuld an der Abwanderung, sondern die Regierung selbst habe durch ihre Unfähigkeit, die wirtschaftliche Lage des Landes zu verbessern, entscheidend zum Anstieg der Emigration beigetragen. Die Supplententaxen seien hierfür geradezu paradigmatisch, denn die Regierung unterstütze nicht das von der Wirtschaftskrise gedrückte 
Land, sondern bürde den Gemeinden mit den Straftaxen neue und unvorstellbar hohe Lasten auf. Daß die Gemeindevertreter die Regierung nicht von ihren Plänen abbringen konnten war für die radikale Opposition ein Beweis mehr, daß die Gemeindeselbstverwaltung nicht existierte und die Venetianer in Wien nicht gehört wurden: Die Gemeindevertreter wurden deshalb aufgefordert, von ihren Ämtern zurückzutreten ${ }^{472}$.

Diese Proklamationen waren inhaltlich und sprachlich fast identisch mit einer Eingabe der Zentralkongregation an Kaiser Franz Joseph, worin um eine Änderung der Rekrutierungspolitik ersucht wurde, um den besitzenden Stand in Venetien nicht an den Bettelstab zu bringen. Auch bei dieser Gelegenheit betonte die Zentralkongregation, daß die Emigranten ihre Heimat nicht aus politischen, sondern aus ökonomischen Gründen verlassen hätten. Sie ersuchte, die schon durch die allgemeinen wirtschaftlichen Umstände so schwer getroffenen Gemeinden nicht noch stärker zu belasten und für etwas verantwortlich zu machen, an dem sie keine Schuld hätten. Podestà Pier Luigi Bembo regte einen mehrjährigen Zahlungsaufschub an und erinnerte Lasser an seine früheren Versprechungen, die schwierige Lage der venetianischen Gemeinden zu berücksichtigen. Er schlug auch die Aufrechnung der ausständigen Taxen gegen die ärarischen Schulden vor ${ }^{473}$. Die Delegaten argumentierten ähnlich:

„Qui si sta tra due pericoli, tra quello di dover pagare e non potere, e l'altro del vedere tutto ad un tratto sospesi i pagamenti dell'erario militare pelle prestazioni dei comuni, minaccia che già una volta fu fatta e che potrebbe diventare reale in seguito. “474

Für die Delegaten waren die Taxen ein erschwerendes Moment in ihrem Bemühen, ein gutes Einvernehmen mit der lokalen Bevölkerung herzustellen. Sie behinderten die Zusammenarbeit mit der lokalen Elite nachhaltig und erschwerten auch die Wahl von Gemeinde- und Kongregationsabgeordneten. Trotz dieser erdrückenden Argumente gewährte die Regierung wieder nur eine Erleichterung: Die Stellvertretertaxen sollten nun doch gegen die ausständigen Kriegsprästationen aufgerechnet werden. Eine vorläufige Abrechnung hatte ergeben, daß bis auf Mantua und Verona, die Naturalien aus dem Ärar erhalten hatten und somit selbst an das Militär verschuldet waren, alle anderen Provinzen vom Staat Entschädigungen zu erwarten

${ }^{472}$ Abschriften der beiden oben zitierten Aufrufe und eines Schmähgedichts im venezianischen Dialekt befinden sich beiliegend zu einem Schreiben Straubs an Toggenburg v. 5. Oktober 1862, HHStA, IB (BM) 227, Z 4119. Über den schlechten Eindruck, den die Supplententaxen auch bei den Austriacanti machten: Pibosio, Il Friuli 211 und 213.

473 Toggenburg an Staatsministerium v. 22. Juli 1862, ASV, PdL 597, XIII/3/2. Beiliegend ein Gesuch der Zentralkongregation v. 12. April 1862 und Bembo an Lasser v. 11. Juli 1862 .

${ }^{474}$ Delegat Jordis (Verona) v. 6. März 1862, ebd. 
hatten. Für diese Provinzen wurde mit Zustimmung der Militärbehörden die Einhebung der Stellvertretertaxen ausgesetzt ${ }^{475}$. Nachdem sich die Schuld des Ärars bei den venetianischen Gemeinden auf drei Millionen Gulden belief und die Schuld an Supplententaxen auf zwei Millionen, war dieser Finanzausgleich zwar möglich, löste das Problem aber nicht.

Ein weiterer Streitpunkt war die Frage, ob die Nachmänner für untaugliche Flüchtlinge durch die zuständige Gemeinde oder durch den gesamten Militärbezirk zu stellen waren. Toggenburg bezeichnete letzteres als unbedingt notwendig, denn eine Stellung der Nachmänner durch die Gemeinden sei „,weder unter Anwendung der für die Heeresergänzung bestehenden Gesetzgebung noch ohne Gefährdung der öffentlichen Ruhe ausführbar" . Er berief sich auf die Kundmachung vom 26. September 1860, in der ausdrücklich die Ersatzpflicht der Stellungsbezirke ausgesprochen worden war ${ }^{476}$, weshalb er auch entgegen den Anordnungen des Kriegsministeriums die Weisung erteilt hatte, die Steuern zwar von den einzelnen Gemeinden einzuheben, die Nachmänner aber auf die gesamten Stellungsbezirke aufzurechnen $^{477}$. Das Ministerium lehnte ab. Toggenburg fuhr nun schweres Geschütz auf und kündigte an, die Eintreibung der Supplententaxen im ganzen Land eigenmächtig zu sistieren, denn die Gemeinden, „welche eigentlich nichts anderes als Steuervereine sind", hätten keinerlei Handhabe, die Emigration von Stellungspflichtigen zu verhindern ${ }^{478}$. Endlich, am 20. Dezember 1862, wies Lasser Toggenburg an, die Einbringung der Supplententaxen nun auch in Verona und Mantua zu sistieren ${ }^{479}$.

Die Regierung gab dem Druck der Verhältnisse nach. Sie ließ nach jahrelangen Diskussionen den Statthalter gewähren und vollzog auch de jure, was Toggenburg de facto schon durchgeführt hatte: Am 5. Jänner 1863 beschloß der Ministerrat einstimmig die vollständige Aufhebung der Supplententaxen ${ }^{480}$. Verwaltungsminister Lasser begründete den endgültigen Rückzug damit, daß die Maßregel ,an dem Mangel der Durchführbarkeit gescheitert" sei. Nach der Gewährung der oben genannten Begünstigungen und Erleichterungen - Bewilligung von Zahlungsfristen, Zahlung durch Banknoten im Nennwert, Abschreibung der Taxen der als untauglich angenommenen Flüchtlinge, schließlich auch Einstellung der zwangsweisen Eintreibung der Steuern und Kompensation durch die Kriegsprästationen

475 Lasser an Toggenburg v. 7. Dezember 1862, ebd.

476 Landesgesetzblatt 1860, Nr. 53.

477 Toggenburg an Staatsministerium v. 14. Dezember 1862, ebd.

478 Ebd.

479 ASV, PdL 597, XIII/3/2.

480 MR II v. 5. Jänner 1863/1, ÖMR V/5, Nr. 308. Siehe dazu auch den Vortrag Lassers v. 29. Dezember 1862, Ah.E. v. 22. Jänner 1863, HHStA, Kab.Kanzlei, KZ 227. 
- war der ursprüngliche Sinn der Maßnahme verloren gegangen. Damit wurde wieder die ursprüngliche und in der ganzen Habsburgermonarchie übliche Regelung eingeführt, daß für jeden Rekrutierungsflüchtling ein Nachmann gestellt werden mußte. Da es aus den vergangenen Rekrutierungen noch ein Minus gab - nur etwa ein Zehntel der geforderten Taxen war bezahlt worden - mußte auf höhere Altersklassen zurückgegriffen werden und Lasser befürchtete „Renitenzen“ in der Bevölkerung und eine neuerliche Zunahme der Stellungsflucht. Dennoch war er für die Aufhebung, weil die Supplententaxen gesetzlich kaum gedeckt waren und die Maßnahme „bisher eigentlich nichts genützt und sich daher als unfruchtbar erwiesen hat". Schließlich mußte er eine schwere Fehleinschätzung der Regierung zugeben, denn die Maßnahme hatte sich ,,wegen des Widerstandes von Seite der Gemeinden und auch wegen der Unerschwinglichkeit der den Gemeinden auferlegten Last als unausführbar gezeigt." Gegen diesen gemeinsamen Antrag von Staats- und Kriegsministerium gab es im Ministerrat keinen Einwand. Toggenburg wurde nach jahrelangen Querelen Recht gegeben. Nur in Tirol wurde der Rückzug der Regierung in dieser Frage bedauert und vor einem neuerlichen Anstieg der Emigration gewarnt ${ }^{481}$. Letztlich hatte sich die politische Linie Schmerlings durchgesetzt, der Venetien wie alle anderen Kronländer behandeln wollte und Ausnahmen ablehnte. Die Regelung war vom Armeekommando angeregt, von der Regierung Rechberg-Gołuchowski eingeführt und von der Regierung Schmerling eine Zeit lang mitgetragen worden. Es ging aber nicht an, Venetien für alle sich im bezug auf Italien ergebenden Probleme verantwortlich zu machen und finanzielle Kompensationen zu fordern. Vielmehr erwies sich diese Haltung der „Falken“ unter den Wiener Politikern als folgenschwerer Irrtum.

Am 21. Februar 1863 richtete die Statthalterei ein Rundschreiben an alle Delegaten, in dem sie zu erhöhter Wachsamkeit aufgefordert wurden, um eine neuerliche Propagandawelle für die Emigration zu verhindern. Auch die Grenzüberwachung durch die Gendarmerie wurde intensiviert ${ }^{482}$.

481 Die Angelegenheit wurde nicht nur im Ministerrat, sondern auch im Staatsrat ausführlich diskutiert und begutachtet. Auch hier stimmte man mit dem Vorschlag des Staatsministeriums vollkommen überein. Siehe dazu: HHStA, J. Staatsrat, Z 3/1863. Zu dem befürchteten Widerstand gegen die Rekrutierung kam es nicht. In den Berichten der Delegaten ist fast ausschließlich von einer problemlosen Rekrutierung die Rede, und die Emigration ging weiter zurück. Auch über ein gehäuftes Auftreten von Selbstverstümmelung wird nichts berichtet. Bekannt ist nur ein Fall aus Cividale, wo es 1862 sieben Burschen gelungen war, wegen „Kahlköpfigkeit“ die Militärbefreiung zu erreichen. Es stellte sich jedoch heraus, daß sie das künstlich herbeigeführt hatten. Vortrag Lassers v. 29. Jänner 1863, Ah.E. v. 7. Februar 1863, ebd. KZ 371 .

482 Statthalterei an Delegaten v. 21. Februar 1863, ASV, PdL 597, XIII/3/1 (Litographie). Non è infondato il sospetto che anche in quest'anno saranno poste in opera dai nemici dell'ordine attive macchinazioni, onde indurre i giovani coscritti ad evadere all'estero; per lo 
Zunächst schien es tatsächlich, als ob viele Rekrutierungspflichtige abwesend wären ,che appartengono esclusivamente alla classe degli artigiani e delle famiglie civili per la massima parte della città ". Scheinbar waren viele in den letzten Tagen vor der Rekrutierung verschwunden, weshalb der Delegat von Padua den Statthalter ersuchte, die Grenzen ganz besonders gut überwachen zu lassen (,,voglia impartire gli ordini più energici e solleciti alle autorità tutte di confine, onde in questi giorni specialmente e durante la leva abbiano a raddoppiare di sorveglianza"). Der Delegat wies die Polizei und die Gendarmerie an, alle männlichen Jugendlichen an den Ausgängen der Stadt zu kontrollieren (,,per colpire quei giovani sui quali potesse cadere il sospetto che tentino di fuggire. " ${ }^{483}$. Dieser alarmierende Bericht aus Padua blieb jedoch ein Einzelfall. Vorsichtsmaßnahmen wurden zwar überall getroffen, doch blieb die Rekrutierungsflucht weit unter den Erwartungen:

„Dai rapporti $[\ldots]$ che a tutt'oggi mi giunsero dai dipendenti Uffici non consta, che siensi avute in argomento risultanze di alcun valore, ed anzi si avrebbe che i Coscritti in generale si presentano volonterosi alle operazioni di leva, e che non si verificarono numerose mancanze. ${ }^{* 484}$

Der Delegat von Belluno bezeichnete den Verlauf der Rekrutierung sogar als exzellent: „L'allegria ed il buon umore sono in tutti i coscritti, non si ebbe la minima perturbazione, la minima dimostrazione." Auch er sprach davon, daß zwar Rekrutierungspflichtige fehlten, ,,specialmente nella classe dei piccoli possidenti e riferibilmente alla città di Belluno", was aber nicht auf den „spirito del tempo recente“ zurückzuführen sei, diese Personen wären vielmehr bereits in den Jahren 1859-1862 emigriert. Aktuell gäbe es nur einen Fall einer versuchten Emigration, der aber fehlgeschlagen sei, der Bursche konnte verhaftet werden, was „ottima impressione nel pubblico“ machte, weil damit der Eindruck erweckt wurde, daß es gelungen sei, einerseits „le mene del partito sovversivo“ zu paralysieren und andererseits die Interessen der Ersatzmänner zu wahren ${ }^{45}$.

\footnotetext{
che a paralizzare siffatte mene è necessario che vengano adottate pronte ed efficaci misure. [...] Lo spirito pubblico degli abitanti della campagna ed il disinganno riportato dai molti che rimpatriarono specialmente negli ultimi tempi, lasciano sperare che non sarà ora agevole l'opera della seduzione."

${ }^{483}$ Delegat (Padua) v. 20. Februar 1863, ebd.

484 Polizeidirektion (Frank) v. 24. Februar 1863, ebd.

${ }_{485}$ Delegat Pino v. Belluno v. 23. Februar 1863, ebd. Ähnlich zufrieden der Delegat von Vicenza: Von den 680 Stellungspflichtigen waren nur drei Personen aus Vicenza unentschuldigt der Stellung ferngeblieben (Delegat v. Vicenza v. 17. Dezember 1863, ebd). In Verona gelang die Festnahme eines gewissen Giuseppe Paparella aus San Martino, der beschuldigt wurde, für die Emigration geworben zu haben (Polizeidirektor Straub v. 3. März 1863, ebd.).
} 
Aus den folgenden Jahren liegen keine Berichte über Rekrutierungsflüchtlinge vor. Die Befürchtungen wegen einer Zunahme der Emigration nach Aufhebung der Supplententaxen hatten sich nicht bewahrheitet. Im Gegenteil, die Auswanderung ging weiter zurück, was zeigt, daß es nur einen bedingten Zusammenhang zwischen Rekrutierung und Emigration gab. Erst 1866 wurde das Thema im Zuge der Kriegsvorbereitungen wieder angesprochen. Obwohl das Landesgeneralkommando in Udine am 2. Mai berichtete, daß die Einziehung der Urlauber und Reservisten problemlos verlaufen sei, befürchtete die Statthalterei das Wiederaufleben der Rekrutierungsflucht. Daher sollte der sonst in Kriegszeiten sistierte Loskauf in Venetien weiterhin möglich sein. Doch das Kriegsministerium lehnte eine Bevorzugung Venetiens gegenüber anderen Kronländern ab. Ebenso der Kommandant der Südarmee, Erzherzog Albrecht, weil dies eine ungerechte Behandlung der Bewohner der anderen Kronländer wäre und die Maßnahme in Venetien selbst „leicht den Anschein einer beabsichtigten Gelderpressung gewinnen könnte." Obwohl der Loskauf also nicht möglich sein sollte, liegen für 1866 keine Berichte darüber vor, daß es in den letzten Monaten der österreichischen Präsenz in Venetien zu einem Anstieg der Rekrutierungsflucht gekommen wäre ${ }^{486}$.

\section{Deserteure aus Italien}

1860 berichteten die Polizeibehörden immer häufiger von Deserteuren aus der italienisch-piemontesischen Armee, die in Venetien Zuflucht suchten. Sie kamen vor allem aus der Lombardei und aus den mittel- und süditalienischen Staaten. Die österreichischen Behörden waren ratlos. Es schien ungünstig, sie in dieser politisch schwierigen Situation in Venetien zu belassen, wo es schon für die einheimische Bevölkerung kaum Beschäftigung

${ }^{486}$ Staatsministerium an Toggenburg v. 26. Mai 1866 sowie Statthalterei an Staatsministerium v. 18. Mai 1866 und Stellungnahme des Armeekommandanten Erzherzog Albrecht v. 26. Mai 1866, ebd. XIII/3/23. Wegen der Einziehung der Reservisten siehe Landesgeneralkommando Udine an Statthalterei v. 2. Mai 1866, ebd. XIII/3/22. Das Kriegsministerium argumentierte folgendermaßen: „Denn die Staatsverwaltung könne in dem Augenblicke der Kriegsbereitschaft, in welchem dieselbe alle Mittel anwendet, die Wehrkraft des Heeres auch numerisch zu verstärken und hierin den Patriotismus der Bevölkerung in erfreulicher Weise unterstützt wird, nicht für eine einzelne Provinz das Zugeständnis machen, daß die Wehrpflichtigen derselben sich vom Heeresdienste loskaufen, selbst nicht auf die Möglichkeit hin, daß dieselben flüchtig werden. “ Außerdem vermutete das Kriegsministerium, daß das Interesse in Venetien gar nicht so groß sein dürfte: „,Denn während in den übrigen Provinzen in den letzten drei Wochen vor Sistierung des Loskaufes - bei der Voraussicht eines möglichen Krieges rasch noch 705 Befreiungstaxen eingezahlt wurden, seien aus dem lombardischvenetianischen Königreiche nur 18 Taxen eingegangen." 
gab. Der Polizeidirektor befürchtete, daß sie in die Kriminalität abgedrängt werden würden und schlug vor, sie in die Schweiz oder in andere Länder der Monarchie abzuschieben oder, wenn sie es wollten, in die österreichische Armee einzureihen ${ }^{487}$. Es liegen nur wenig verläßliche Angaben darüber vor, um wie viele Personen es sich dabei handelte, zumindest anfangs dürfte es jedoch eine eher geringe Zahl gewesen sein, denn die österreichische Verwaltung beschäftigte sich nur am Rande mit diesem Problem. Viele der einsickernden Italiener entgingen der Aufmerksamkeit der Behörden, weil sie sich in die schwer zugänglichen Gebirgsgegenden zurückzogen und dort zu vagabundierenden Banden zusammenschlossen. Nach dem Fall von Gaeta im Februar 1861, der Vertreibung des bourbonischen Königs und der Ausrufung des Königreichs Italien im März häufen sich die Berichte über die illegale Immigration. Im Sommer 1861 berichtete der Polizeiminister, daß „die Fälle, daß gewesene königlich neapolitanische Soldaten, welche nach dem Fall von Gaeta zwangsweise in die sardinische Armee eingereiht wurden, aus den Reihen dieser Armee desertieren und auf österreichisches Gebiet sich begeben" immer häufiger wurden, der Polizeiminister sprach von etwa 15 festgenommenen italienischen Deserteuren in zwei Wochen. Was sollte mit ihnen geschehen? Darüber war man sich weder in Venedig noch in Wien im klaren. „Die meisten derselben äußerten den Wunsch, in k.k. Kriegsdienste aufgenommen zu werden" - dazu konnten sich die verantwortlichen Militärs aus Angst vor italienischer Spionage nicht durchringen. Viele baten, nach Rom abgeschoben zu werden. Auch das war unausführbar, „da sie von allen Geldmitteln entblößt waren und ihnen eine Reiseunterstützung weder von den k.k. österreichischen Behörden noch von den diesfalls in Anspruch genommenen dermal noch fungierenden k. sizilianischen Konsularämtern gewährt werden konnte". Rechtlich war die Lage klar: Nach Artikel XVII des Züricher Friedensvertrages waren Deserteure aus der piemontesischen Armee an Piemont-Italien auszuliefern. Da aber Italien österreichische Deserteure nicht auslieferte, wollten auch die österreichischen Behörden die in Venetien aufgegriffenen Personen nicht nach Italien abschieben. Der Polizeiminister stellte fest, daß nichts anderes übrig bleibe, als diesen Leuten den „Aufenthalt auf österreichischem Gebiete, in so fern in einzelnen Fällen nicht polizeiliche Bedenken dagegen sprechen, zu gestatten“. Damit war die Angelegenheit jedoch nicht erledigt, denn es mußte „diesen Leuten eine angemessene Unterkunft und die Möglichkeit, sich die Mittel zum Lebensunterhalte durch eigene Tätigkeit zu erwerben", geboten werden. Die Mehrzahl der in Venetien aufgegriffenen Personen wurden nach Triest gebracht, wo sie in der Schiffswerft Tonello und im

\footnotetext{
${ }^{487}$ Bericht Straubs v. 27. Juni 1860, ebd. 471, XV/7/28.
} 
Lloydarsenal Beschäftigung fanden. Aber auch dort waren nicht unbegrenzt Arbeitsplätze vorhanden:

„Für den Fall aber, als derlei Desertionen sich mehren sollten, würde die Versorgung solcher Leute bedeutenden Schwierigkeiten unterliegen. Da dieselben bloß italienisch sprechen, so könnten sie füglich nirgends anders als in den Küstenländern des adriatischen Meeres verwendet werden. In diesen Gegenden sind aber mehr als genügend derlei Arbeitskräfte vorhanden und wären dermalen Personen nur schwer aufzufinden, welche sich freiwillig herbeilassen würden, Leuten, die aus Liebe zu ihrem legitimen König die Fahnen einer usurpatorischen sardinischen Regierung verlassen haben, Beschäftigung zu geben. Böser Wille einerseits und Furcht andererseits tun das ihrige, um von der Unterstützung sardinischer Deserteure abzuhalten."

Es schien daher keine andere Möglichkeit zu bleiben, als diese arbeitslosen Neapolitaner zur österreichischen Armee einzuziehen ${ }^{488}$. Schon mit kaiserlicher Entschließung vom 14. Mai 1860 war festgelegt worden, daß Deserteure aus der Lombardei und den zentralitalienischen Staaten in die k.k. Armee eingereiht werden sollten. Dem Wunsch des Polizeiministers, diese Regelung auch auf die neapolitanischen Flüchtlinge auszudehnen, entsprach der Kriegsminister damals aber nicht. Am 15. Mai 1860 hatte das Innenministerium im Einvernehmen mit dem Außen- und Polizeiministerium in einem Erlaß an die Statthalterei bestimmt, „daß Deserteure aus sardinischen Staaten, Toskana, Modena und Parma sowie aus den päpstlichen Legationen in Österreich zu dulden sind, vorausgesetzt, daß keine polizeilichen Bedenken gegen ihren Aufenthalt daselbst obwalten, widrigens wohl deren Abschaffung, nicht aber deren Auslieferung zu erfolgen hätte“. Diese Regelung galt auch für die neapolitanischen Deserteure. Die Behörden im Küstenland und in Venetien wurden angewiesen, sie

„,nach Möglichkeit in irgend eine Arbeit unterzubringen und ihnen nötigenfalls auch aus Staatsmitteln den notwendigsten Lebensunterhalt zu gewähren [...] Gleichwohl mußte dies seine Grenzen finden und waren bei dem Mangel anderweitiger Beschäftigung für die gedachten Flüchtlinge und bei dem Überhandnehmen derselben außer der Überbürdung des durch dieselben ins Mitleid gezogenen Staatsschatzes für die kaiserlichen Behörden überhaupt ernste Verlegenheiten zu besorgen."

Am 8. Juli 1861 lehnte es das Kriegsministerium neuerlich entschieden ab, Neapolitaner in großer Zahl in die österreichische Armee einzureihen, weil „ein großer Teil dieser mitunter auch aus Abenteurern verschiedener Nationalitäten bestehenden Überläufer in seinen Gesinnungen und seiner Denkungsart im hohen Grade verdorben sei und von der Aufnahme so bedenklicher Elemente in die k.k. Armee verderbliche Folgen zu besorgen wären. "489 Einige wenige Neapolitaner wurden dann doch aufgenommen.

488 Polizeiminister an Kriegsminister v. 4. Juli 1861, HHStA, IB (BM) 184, Z 967.

489 HHStA, IB (BM) 226, Z 4077. 
Ein Teil wurde in die österreichische Armee, der größere Teil in die modenesische Brigade eingereiht. Von Jänner bis Ende November 1861 waren es 196 Mann. Ende 1861 verlautete der neapolitanische Hof, daß diese Leute „den lebhaften Wunsch hegen, in die Heimat zurückzukehren“. Der Kriegsminister hatte nichts dagegen einzuwenden, wies aber darauf hin,

„daß jene Leute bei ihrem Eintreffen in Triest sofort an irgend eine dazu gewählte Person übergeben werden, welche ihre Überwachung, Verpflegung und Einschiffung zur Rückkehr in die Heimat besorgt, damit dieselben nicht unnütz und zum Nachteile des Militärärars in Triest sich aufhalten. Auch halte ich es für bedenklich, wenn diese Neapolitaner in der k.k. Militärbekleidung nach ihrer Heimat gesendet würden; es müßte daher jedenfalls die Vorkehrung getroffen werden, dieselben in Triest mit entsprechender Zivilkleidung zu versehen und ihnen die österreichische Montur abzunehmen“490.

Der Kriegsminister faßte die Bedenken gegen eine Aufnahme von Neapolitanern in die österreichische Armee in seinem Vortrag vom 2. Februar 1863 nochmals zusammen: Er sprach von 1852 Überläufern aus Italien, darunter 444 aus der Lombardei. Davon habe man 863 in die Armee eingereiht - es handelte sich größtenteils um Lombarden und Flüchtlinge aus den ehemals mittelitalienischen Staaten, kaum um Neapolitaner -, doch keineswegs zur Zufriedenheit der Militärkommanden. Zwar bestünde kein Anlaß, „die politische Gesinnung dieser Überläufer in Zweifel zu ziehen“, doch wären sie nicht wirklich verläßlich. Auch um den „militärischen Wert“ dieser Leute sei es schlecht bestellt. Einige desertierten auch aus der österreichischen Armee, wobei besonders die Neapolitaner „,durch seltene Verschmitztheit hervorragen", was sich auch auf die Moral der anderen Soldaten negativ auswirkte ${ }^{491}$. Auch in die österreichische Finanzwache wurden italienische Deserteure aufgenommen, was aber, da sie nicht die österreichische Staatsbürgerschaft besaßen, einen kaiserlichen Gnadenakt erforderlich machte ${ }^{492}$.

Die Lösung des Flüchtlingsproblems durch eine generelle Einreihung in die Armee war also nicht möglich, daher ordnete ein Erlaß des Polizeimi-

490 Kriegs- an Außenminister v. 24. Dezember 1861, KA, KM-Präs., Z 5362.

491 Vortrag des Kriegsministers v. 2. Februar 1863, ebd. Mit Ah.E. v. 6. Februar 1863 wurde der Punkt 4 der Ah.E. v. 14. Mai 1860 aufgehoben und bestimmt, daß italienische Deserteure nicht mehr in die österreichische Armee einzureihen wären.

492 Vortrag des Finanzministers v. 9. Mai 1862, Ah.E. v. 14. Mai 1862, HHStA, Kab.Kanzlei, KZ 1357. Hier werden die Lebensgeschichten von sechs Einwanderern geschildert, die einfache Leute waren, teilweise Familienväter, die in der neapolitanischen Armee tätig gewesen waren und nicht in die italienische Armee übernommen werden wollten. Auch aus dem Jahr 1864 ist ein ähnlicher Fall dokumentiert: Vincenzo Masotti wurde unter Nachsicht der Staatsbürgerschaft in die Finanzwache aufgenommen. Vortrag des Finanzministers v. 25. April 1864, Ah.E. v. 4. Mai 1864, ebd. KZ 1278. 
nisters vom 15. Juli 1861 den Statthaltereien von Venedig, Triest und Zara an,

„daß wenn die Zuflucht solcher Flüchtlinge andauern oder auf einmal in großer Stärke erfolgen sollte, diese bloß des italienischen Idioms mächtigen Fremden, wenn ihre Unterbringung im Verwaltungsgebiete, wo sie die kaiserliche Grenze hereinpassieren, nicht möglich wäre, in den übrigen Küstenländern des adriatischen Meeres verteilt und dahin verschoben werden können, worüber jedoch vorläufig mit dem Chef des Kronlandes, wohin die Verschiebung geschehen soll, zur Vorbeugung von Verlegenheiten das Einvernehmen zu pflegen wäre. “493

Im Herbst 1861 schien sich ein Ausweg abzuzeichnen. Der königlichneapolitanische Gesandte in Wien wollte ein neapolitanisches Freischärlerkorps organisieren. Er schlug vor, die neapolitanischen Flüchtlinge von Curzola aus auf den Gargano zu bringen, von wo aus sie ihren Partisanenkampf gegen die italienische Armee aufnehmen sollten. Der Polizeiminister ließ die Statthalter von Venedig und Zara am 1. November 1861 wissen, daß von österreichischer Seite dagegen nichts einzuwenden sei, daß aber die ganze Aktion „,möglichst unauffällig und ohne Einmischung der kaiserlichen Behörden zu geschehen hätte." Dieser Versuch verlief jedoch im Sande, und das Flüchtlingsproblem verschärfte sich durch die Krise der Triestiner Werft. Den dort beschäftigten Neapolitanern drohte die Arbeitslosigkeit:

„Die Bemühungen sie anderweitig im Küstenlande und in Dalmatien unterzubringen sind ohne Erfolg geblieben. Es wurden daher, um den gedachten Individuen, wo möglich im Innern der Monarchie Erwerbsquellen zu eröffnen, die Länderchefs in Steiermark, Kärnten und Krain aufgefordert, in den dortländigen Fabriksetablissements bei Bauten u.d.gl. Nachforschungen zu pflegen, ob denselben mindestens nicht für einige Zeit Beschäftigung verschafft werden könne. Der Statthalterei in Triest aber wurde bedeutet, daß die Kosten für den Unterhalt der erwerbslos werdenden Flüchtlinge aus dem öffentlichen Sicherheitsfonde jedoch mit größer Sparsamkeit zu bestreiten seien. " 494

52 Neapolitaner verließen Triest und zogen nach Laibach weiter, wo sie bei öffentlichen Bauvorhaben untergebracht werden sollten. Die Neapolitaner „entfernten sich jedoch in 2 Partien alsbald in der Richtung nach Steiermark." Bald meldete die Grazer Statthalterei, daß sie in der steirischen Hauptstadt und in Marburg eingetroffen wären. Sie sollten dort „strenge zur Arbeit verhalten“ werden, und man ließ sie wissen, „daß sie, im Falle sie sich den behördlichen Anordnungen nicht fügen wollten, als des bisher genossenen Schutzes unwürdig unnachsichtlich aus den k.k. Staaten entfernt werden würden." Die Unzufriedenheit war auf allen Seiten groß. Die

\footnotetext{
${ }_{493}$ Votum des Polizeiministeriums, undatiert, HHStA, IB (BM) 226, Z 4077. Der Erlaß wird zitiert, es liegt aber kein Entwurf bei.

${ }^{494}$ Ebd.
} 
Neapolitaner fanden kaum Arbeit, und dem Staat kostete ihr Unterhalt erhebliche Summen. Da ihnen auch vorgeworfen wurde, daß sie ,gegen den gewöhnlichen, aber nicht niedrigen Taglohn wenig Lust zur Arbeit zeigten und sich unter ihnen eine gewisse Unzufriedenheit zeigte", fragte die Grazer Statthalterei in Wien an, ob nicht diejenigen, ,welche sich den Anordnungen der hieländigen Behörden nicht fügen, sich als arbeitsscheu und sonst der hiesigen Gastfreundschaft unwürdig erweisen", ins Ausland abzuschieben wären, wobei insbesondere auf Korfu hingewiesen wurde. Die Beschwerden aus der Steiermark über die dortigen Neapolitaner mehrten sich, „,und begannen dieselben auch insofern unruhig zu werden, als sich einige zur Rückkehr in ihr Vaterland meldeten, andere aber um ihre Transportierung nach bestimmten Orten Südtirols oder Oberitaliens ansuchten." Auch aus Kärnten gab es Meldungen, daß laufend Deserteure über Pontebba einsickerten, die offenbar vom Polizeikommissariat Udine nach Villach und Klagenfurt geschickt wurden, um dort Arbeit zu suchen, wobei ihnen die Reisekosten und die Verpflegung bezahlt wurde ${ }^{495}$, ohne daß aber die Kärntner Behörden davon informiert wurden.

Das Außenministerium stimmte am 10. Juni 1862 der Ausschiffung der neapolitanischen Flüchtlinge nach Korfu zu. Die Statthalter der Länder, wo es neapolitanische Flüchtlinge gab, wurden am 4. Juli beauftragt, die erforderlichen Transportkosten zu bestreiten und die Neapolitaner mit Paßdokumenten auszustatten. Die Statthalterei in Venedig wurde außerdem am 14. Juli angewiesen, keine Neapolitaner mehr nach Triest zu schicken, ,,indem sich dort ohnedies 124 solcher Individuen, meist erwerbslos, befinden und hiedurch der dortigen Polizeibehörde Verlegenheiten erwachsen." Am gleichen Tag wurde mit der Einschiffung nach Korfu begonnen. Aus Venetien kamen keine Neapolitaner, da es nach Auskunft von Statthaltereivizepräsident Marzani dort nur drei „gefährliche“ italienische Deserteure gab, und zwar zwei Untertanen des Kirchenstaates und einen Sarden „,che possano divenire pericolosi all'ordine e tranquillità pubblica“. Die Abschiebungen nach Korfu mußten schon Ende August wieder eingestellt werden, weil die dortigen Behörden politische und diplomatische Schwierigkeiten mit Italien befürchteten.

Aber auch innerhalb der Habsburgermonarchie wurde es immer schwieriger, die Leute unterzubringen. Nachdem die Tiroler Statthalterei einen Aufnahmestopp für Flüchtlinge erlassen hatte, wurden sie nach Salzburg gebracht, aber ,,auch dortlands [fehlte es] an öffentlichen Arbeiten, bei

\footnotetext{
${ }^{495}$ Polizeiminister an Statthaltereivizepräsident Marzani v. 20. September 1862, ASV, PdL 597, XIII/3/6. Grund für das Schreiben war eine Beschwerde der Klagenfurter Behörden, die vom Eintreffen der Italiener von der Polizeistelle in Udine nicht informiert worden waren.
} 
welchen solche Flüchtlinge in größerer Anzahl Beschäftigung finden könnten." Ein Vier-Punkte-Plan des Polizeiministeriums (Zurückweisung neuer Flüchtlinge, Abschiebung der Arbeitsscheuen, Unterstützung der Heimkehrwilligen, gleichmäßige Verteilung der Verbleibenden) blieb Wunschdenken: Weder wurden italienische Deserteure an der Grenze abgewiesen noch kam es zu umfangreicheren Abschiebungen ${ }^{496}$.

Auch abgesehen von den Neapolitanern gab es nicht so wenige (Reichs-) Italiener in der Habsburgermonarchie. Sie waren teilweise in der Armee und bei der Finanzwache tätig, teilweise arbeiteten sie in den Schiffswerften und an der Errichtung von Befestigungsbauwerken mit. Einige verdienten sich ihren Lebensunterhalt mit Feldarbeiten. Da viele keinen festen Aufenthaltsort hatten, war ihre Überwachung schwierig. Obwohl die Behörden verpflichtet waren, regelmäßig „Immigrantenausweise“ zu erstellen, gibt es nur annäherende Angaben über ihre $\mathrm{Zahl}^{497}$. Aus diesen Immigrantenausweisen geht hervor, daß es sich fast ausschließlich um einfache Burschen, meist Dorfbewohner im Alter von knapp über 20 Jahren, handelte. Alberto M. Rossi stellte fest, daß von 132 italienischen Flüchtlingen, die den Bezirk Adriano passierten, 112 Bauern und die anderen Handwerker waren. Ihr Hauptmotiv war die Rekrutierungsflucht. Viele zeigten sich bereit, in die österreichische Armee einzutreten und gegen die italienische Armee zu kämpfen. Gelegentlich spielten auch pazifistische Motive und die prinzipielle Verweigerung des Dienstes mit der Waffe eine Rolle ${ }^{498}$. Am 2. November 1862 wurde in Italien eine Amnestie für Deserteure erlassen. Auch sie löste das Problem nicht, weil sie so eng gefaßt war, daß sie nur auf die wenigsten in Österreich befindlichen Italiener anwendbar war ${ }^{499}$. Außerdem protestierte Anfang 1863 das Außenministerium gegen Abschiebungen nach Italien und wies darauf hin, ,wie wenig eine rücksichtslose Behandlung der nea-

496 Marzani an Mecséry v. 22. August 1862, HHStA, IB (BM) 220, Z 2888, und vor allem ebd. $226, \mathrm{Z} 4077$.

${ }^{497}$ In der Literatur ist die Rede von 500 bis zu 4663 Italienern. Vgl. Alberto M. RossI, Emigrazione e renitenza alla leva all'indomani dell'unificazione: Il caso dei rifugiati clandestini nel Lombardo-Veneto, in: Giusti, Il Lombardo-Veneto 329-336. Polizeidirektor Straub und das Polizeiministerium berichteten über 2500 Flüchtlinge, ebd. 226, Z 4077/7884 und Straub an Toggenburg v. 16. November 1862, ebd. 7928. Die von Jean Pierre JouveT, Il Lombardo-Veneto e l'Italia nel Risorgimento, in: L'Arena. Il Giornale di Verona (1991) 11 , angegebene Zahl von 4633 allein im Jahre 1861 scheint jedenfalls zu hoch gegriffen. Toggenburg gibt im Jänner 1863 die Zahl der sich in Venetien aufhaltenden Neapolitaner mit 286 an. Toggenburg v. 13. Jänner 1863, HHStA, IB (BM) 226, Z 4077/7884 u. 7928. Ein Verzeichnis dieser Personen liegt bei.

498 Die Vermutungen von Rossi, Emigrazione e renitenza, werden durch Stellungnahmen österreichischer Behörden indirekt bestätigt.

499 Straub an Toggenburg v. 30. Dezember 1862. Dieser und ein früherer Bericht Straubs in HHStA, IB (BM) 226, Z 4077/7884 und /7928. 
politanischen Flüchtlinge, welche auf österreichischem Gebiete ein Asyl gegen die Übergriffe der usurpatorischen sardinischen Regierung gesucht haben, mit den konservativen Grundsätzen des österreichischen Gouvernements im Einklange stünde und welcher für dasselbe höchst ungünstige Eindruck dadurch hervorgebracht würde. " ${ }^{500}$ Ab 1863 nehmen die Akten über neue Einwanderer und über Abschiebungen deutlich $a b^{501}$.

Italienische Deserteure in Venetien 1860-1862502

\begin{tabular}{|l|c|c|c|c|c|}
\hline & Lombarden & Piemontesen & $\begin{array}{c}\text { Zentral- } \\
\text { Italiener }\end{array}$ & Neapolitaner & Summe \\
\hline 1860 & 132 & 30 & 52 & & 214 \\
\hline 1861 & 241 & 48 & 941 & & 1230 \\
\hline 1862 & 71 & 22 & 130 & 185 & 408 \\
\hline Summe & 444 & 100 & 1123 & 185 & 1852 \\
\hline
\end{tabular}

Nach dem Friauler Putsch wurden die Maßnahmen gegen Flüchtlinge aus Italien erheblich verschärft und die Grenzen für Einwanderer geschlossen. $\mathrm{Ob}$ das auch für italienische Deserteure gelten sollte, war umstritten. Toggenburg meinte, wenn Ausländern ohne Ausweise der Eintritt in das österreichische Staatsgebiet verweigert werde, könne man nicht jemanden, nur weil er sich als Deserteur der piemontesischen Armee ausgab, unbehelligt einreisen lassen:

„Dieses Zugeständnis wird vielfach mißbraucht. Die Zahl derjenigen, welche die Anhänglichkeit an ihren legitimen Souverän nach Österreich herüber drängte, ist offenbar eine verschwindend kleine gegenüber der Menge der anderen, welche teils der Widerwillen gegen jede militärische Disziplin, teils die Furcht vor bevorstehenden Strafen, teils andere unlautere Motive veranlaßten, sich in diese Provinzen einzuschleichen. Daß eine Konstatierung der wirklichen Desertion aus dem piemontesischen Heere und der Motive, welche sie veranlaßten in den seltensten Fällen möglich ist, liegt wohl in der Natur der Sache; so kam es denn, daß sich unter dem Deckmantel der Eigenschaft als piemontesische Deserteure sehr viel arbeitsscheues, erwerb- und mittelloses Gesindel, darunter viele in jeder Beziehung gefährliche Individuen, Verbrecher, Spione, Emissäre etc. in diesem Kronlande herumtrieben. Gegen einzelne solcher Individuen ist wohl bereits die Außerlandschaffung durch Tirol nach der Schweiz verfolgt worden."

500 Memorandum des Außenministeriums als Beilage zu einem Akt v. 7. Jänner 1863, ebd., Z 4077/130. Über Abschiebungen siehe ebd. 226, Z 4077/7884 und /7928273, Z 6902, 285, Z 8330 und Z 9997.

${ }_{501}$ Frank an Statthalterei v. 28. Februar 1865, ebd. 347, Z 388. Viele italienische Flüchtlinge waren abgeschoben worden oder in andere Kronländer abgewandert, sodaß sich Anfang 1865 nur mehr zwei Italiener, die aus Staatsmitteln erhalten werden mußten, in Venetien befanden.

502 KA, KM-Präs. Z 401/1863

503 Toggenburg an Mecséry v. 27. Jänner 1865, HHStA, IB (BM) 347, Z 388. 
Armeekommandant Benedek vertrat die Ansicht, daß Personen, die in Montur an der Grenze auftauchten, militärische Abzeichen oder Dokumente mit sich führten, durch die sie ihre Zugehörigkeit zur italienischen Armee nachweisen konnten, unbedingt aufgenommen werden müßten, da auch Italien Deserteure aus Österreich ins Land ließ und nicht an der Grenze zurückschicke. Gendarmerie und Polizei wiederum fürchteten, daß auf diese Weise die italienische Regierung und die Revolutionskomitees „am leichtesten Spione und Emissäre in dieses Land einschwärzen können“:

„Es wird dies um so auffälliger, als jene politischen Motive, welche in den ersten Jahren Lombarden, Modeneser und Neapolitaner zur Fahnenflüchtigkeit verleitete, ebenso wenig als die angeblich schlechte Behandlung, die wahre Ursache sein dürfte und wohl hie und da andere Absichten hier zu Grunde liegen müssen. [...] Aber auch abgesehen von diesen politischen Bedenken dürfte es einfach nicht im Interesse der öffentlichen Sicherheit liegen, Leuten, welche alle Hilfsmittel entbehren und über deren Vorleben sowie über die wahren Ursachen ihrer Desertion man nie das Wahre erfahren kann, den freien Aufenthalt und das Vagieren im Lande unbedingt zu gestatten." ${ }^{004}$

Nach einer Verständigung zwischen den zuständigen Ministerien (Polizei-, Staats-, Außen- und Krieg) wurde den Wünschen des Statthalters und des Polizeidirektors entsprochen, ,piemontesischen Deserteuren ohne Unterschied der Kategorie" den Eintritt nach Österreich zu verweigern, wobei auch keine Rede mehr davon war, daß Deserteure in Montur nach Österreich gelassen werden sollten ${ }^{505}$. In der Praxis wurden dann doch nicht alle nach Italien zurückgeschickt. Wenn sie sich allerdings der „hierländigen Gastfreundschaft unwürdig erwiesen", drohte ihnen die Abschiebung in die Schweiz. Es waren das aber nur wenige Fälle ${ }^{506}$.

Die Einwanderung aus Italien war 1865 weitgehend zum Stillstand gekommen. Vor Ausbruch des Krieges von 1866 stieg die Befürchtung, daß

504 Auszüge aus einer Note des Obersten Greipel v. 17. Februar 1865, ebd. Siehe dazu auch Straub an Toggenburg v. 9. März 1865, ASV, PdL 597, XIII/3/6. Rossi, Emigrazione e renitenza 334, faßt zusammen: „Sintetizzando fortemente, si può dire che, pur non rifiutando loro l'asilo politico queste mantengono verso di essi un atteggiamento piuttosto cauto e diffidente. Renitenti e disertori vengono trattati, in ultima analisi, come "tollerati." Si tratta di una massa eterogenea per provenienza, costumi e mentalità, nella quale è possibile anche l'infiltrazione da parte di agenti ed emissari del governo di Torino. Per di più si tratta di diseredati, privi di mezzi di sostentamento, di lavoro e di un tetto."

505 Siehe dazu Außenministerium an Kriegsministerium v. 25. März 1865, KA, KM-Präs. 1865, 53-7/1. Hier werden die verschiedenen Standpunkte, vor allem diejenigen Toggenburgs und Benedeks, zusammengefaßt.

${ }_{506}$ Mit Ausnahme einiger Andeutungen im Aktenbestand des ASV, PdL 597, XIII/3/6. Rossi, Emigrazione e renitenza 331, der die Immigration in das Polesine anhand der Akten des Delegationsarchivs untersuchte und konstatierte, daß ab 1865 keine Berichte über Einwanderer aus Italien vorliegen. 
wieder verstärkt Deserteure versuchen könnten, nach Österreich einzureisen. Toggenburg hielt zunächst an den verschärften Vorschriften fest. Benedek meinte jedoch, „daß ihm bei den gegenwärtigen Verhältnissen die Zurückweisung sardinischer Deserteure und Rekrutierungsflüchtlinge unbedingt unzulässig erscheine und daß er daher deren Internierung in einer rückwärtigen Provinz befürworten müsse." Toggenburg gab dem militärischen Druck nach und ordnete an, daß die italienischen Deserteure ab sofort nicht mehr zurückgewiesen, sondern festgenommen werden sollten, ,und wenn sie nicht verlangen in die österreichische Armee einzutreten, nach eigener Wahl in eines der österreichischen Kronländer nichtitalienischer Zunge“ oder in die Schweiz gebracht werden sollten, „denn es scheint mir keinesfalls anzugehen, daß solche Leute sich im lombardisch-venetianischen Königreiche frei herumtreiben. " ${ }^{007}$ Überraschenderweise lehnte Staatsminister Belcredi die vom Armeekommando geforderte und von Toggenburg widerwillig akzeptierte Aufhebung des Verbots, italienische Deserteure in Österreich aufzunehmen ab, „nachdem sich herausgestellt hat, daß die Nachteile der Aufhebung dieses Verbots deren Vorteile überwiegen würden." "508

Das Beispiel der italienischen Flüchtlinge, zu dem sich in diesen Jahren noch die Fluchtwelle nach Galizien wegen des polnischen Aufstands gesellte, zeigt, wie die österreichische Verwaltung mit dem Flüchtlingsproblem umging. Flüchtlinge wurden zwar aufgenommen und sie erhielten auch staatliche Unterstützungen, im Grunde waren und blieben sie aber ungeliebte Gäste, die man so schnell wie möglich wieder los werden wollte. Nur politisches Prestigedenken hielt die Regierung davon ab, sie sofort wieder nach Italien abzuschieben, hatte man mit den italienischen Flüchtlingen doch den lebenden Beweis in Händen, daß es auch im neu gegründeten Königreich viele Regierungsgegner gab, die es vorzogen, beim Erzfeind Österreich Zuflucht zu suchen. Besonders deutlich wird das am Spezialfall der neapolitanischen Flüchtlinge, weil die Behörden hier ganz besonders planlos agierten und eigentlich nur versuchten, sich unliebsamer Einwanderer ohne allzu große humanitäre Rücksichten zu entledigen.

Ein Sonderfall anderer Art waren die sogenannten „modenesischen Truppen", deren Anwesenheit in Venetien auf ein 1847 zwischen Österreich und Modena abgeschlossenes Militärbündnis zurückging, aufgrund dessen die Habsburgermonarchie für die mit ihrem Herzog von Modena nach Venetien geflüchteten Truppen vorschußweise zu sorgen hatte. 1859 trat der Vertragsfall ein. Franz V. von Österreich-Este, Herzog flüchtete mit ca. 3500 Mann nach Venetien. Die Kosten der Erhaltung dieser Truppen belie-

\footnotetext{
507 Toggenburg an Polizeiminister v. 21. Mai 1866, ebd.

508 Belcredi an Toggenburg v. 30. Mai 1866, ebd.
} 
fen sich auf immerhin 80.000 Gulden monatlich ${ }^{509}$. Im August 1860 ließ Außenminister Rechberg den Herzog von Modena wissen, „daß die vorschußweise Verpflegung seiner Truppen nicht in das Infinitum auf diesseitige Kosten stattfinden könne und daß nach Ablauf irgend einer festzusetzenden Frist rücksichtlich dieser Truppen doch irgend ein Beschluß gefaßt werden müsste." ${ }^{10}$ Den Zivilbehörden waren die fremden Truppen in Venetien ein Dorn im Auge, denn die Polizeibehörden konnten bei den häufig vorkommenden Zusammenstößen mit der Bevölkerung oder bei kriminellen Handlungen, die von modenesischen Soldaten begangen wurden, nicht eingreifen, da sich der Herzog darauf berief, daß seine Armee über ein eigenes Militärgericht verfügte. Nach Meinung der österreichischen Behörden war das aber nur für interne Angelegenheiten zuständig und nicht für strafbare Handlungen, die modenesische Soldaten an österreichischen Untertanen begingen. Man einigte sich schließlich auf eine gemeinsame Kommission, die in diesen Fällen ermitteln sollte. Das Gerichtsverfahren erfolgte weiterhin vor einem modenesischen Militärgericht, das Urteil mußte aber von Armeekommandant Benedek ratifiziert werden ${ }^{511}$.

1862 wurde eine Reduktion sowohl der Diäten der Soldaten und Offiziere als auch des Pferdestandes durchgesetzt. Die Regierung beschloß, die Subvention von monatlich 70.000 Gulden auf keinen Fall zu überschreiten. Die Truppe wurde um 250 Mann verringert. Gleichzeitig kam es aber durch die Emigration aus Modena zu Neuzugängen, deren Zahl höher war als die der Entlassungen ${ }^{512}$. Im gleichen Jahr schlug die Zentralkongregation vor, das Problem der durch die Rekrutierungsflucht fehlenden Rekruten durch die Integrierung der in Venetien befindlichen modenesischen Truppen in die reguläre Armee zu kompensieren ${ }^{513}$. Für die Militärs stand aber eine Inkorporierung dieses schlecht bezahlten und militärisch wenig brauchbaren Truppenkörpers in die österreichische Armee nie zur Diskussion: „Die ungenügende Bewaffnung und Munition, mangelnde Fuhrwerke und Dienstpferde, mangelhafte Feldausrüstung etc." ließen das nicht ratsam erschei$n^{n}{ }^{514}$. Die Militärbehörden sahen die modenesischen Truppen als Kern „einer italienischen Legion“ für den Fall eines Krieges gegen das Königreich

${ }_{509}$ Siehe dazu die MK v. 10. Dezember 1859/10, ÖMR IV/1, Nr. 74 sowie den Vortrag Rechbergs v. 20. Jänner 1860, Ah.E. v. 27. Jänner 1860, HHStA, Kab.Kanzlei, KZ 258, sowie KA, KM-Präs. 1861, Z 3985, 5048, 5259, 4413 und 5103.

510 Vortrag Rechbergs v. 10. August 1860, Ah.E. v. 15. August 1860, HHStA, Kab.Kanzlei, KZ 2608. Vgl. auch BLAAs, Italienische Frage 201f.

511 Siehe dazu im KA, KM-Präs. 1861, Z 5048, 5016.

512 Ebd. 1862, Z 170, 368 und 861.

513 Toggenburg an Staatsministerium v. 22. Juli 1862, ASV, PdL 597, XIII/3/2. Beiliegend ein Gesuch der Zentralkongregation v. 12. April 1862.

514 Armeekommando Verona an Kriegsministerium v. 31. Mai 1861, KA, MKSM, Z 2039/ 1861. 
Italien, hielten den hohen Truppenstand in Friedenszeiten aber für überflüssig. Es wurde auch immer schwieriger, die hohen Ausgaben für die modenesischen Truppen im Reichsrat zu rechtfertigen. Im Juni 1862 stimmte der Finanzausschuß zwar dem Budget für die Brigade zu, allerdings drängten die Abgeordneten darauf, diesen Zustand bis zum Ende des Verwaltungsjahres $1862 \mathrm{zu}$ beenden. Die Verhandlungen mit dem Herzog von Modena zogen sich jedoch in die Länge. Der Herzog meinte mit den 70.000 Gulden nicht das Auslangen finden zu können, forderte weitere Subventionen und appellierte an die "Gerechtigkeitsliebe und das Wohlwollen" des Kaisers. Franz Joseph erklärte daraufhin die Erhaltung der modenesischen Brigade zur „Ehrensache“ Österreichs ${ }^{515}$. Die offensichtlich uneinbringliche Forderung an den modenesischen Staatsschatz wuchs immer mehr an, auch weil der Truppenkörper durch die Einreihung von Flüchtlingen aus Italien größer wurde. Auch die Verpflegungskosten stiegen ständig. Das Landesgeneralkommando in Udine wurde deshalb nochmals darauf aufmerksam gemacht, daß die Zahlungsraten ab 1. März 1862 „monatlich die Summe von 70.000 fl. auf keinen Fall“ überschreiten dürften ${ }^{516}$. Der Druck des Reichsrates wurde schließlich so stark, daß der Truppenkörper nicht mehr länger erhalten werden konnte, und der Herzog von Modena schließlich die Auflösung akzeptieren mußte, die am 25. Oktober 1863 verfügt wurde. Diejenigen, die nicht nach Modena zurückkehren wollten und bereit waren, in österreichische Dienste überzutreten, wurden in die Finanzwache übernommen, wo man von ihnen als ihrem Herrscher auch in schwierigen Zeiten treu gebliebenen Italienern gute Dienste erwartete ${ }^{517}$.

\section{Flucht aus Venetien}

Nach dem Krieg des Jahres 1859 setzte in Venetien eine Auswanderungswelle ein, die zunächst spontan und unorganisiert war. Viele Anhänger der italienischen Nationalstaates verließen, wie sie dachten nur vorübergehend

515 MR v. 6. Mai 1862/1, ÖMR V/3, Nr. 229, vgl. auch MR III v. 2. September $1861 / 8$, ÖMR V/2, Nr. 117 und MR I v. 16. Jänner 1862/3, ÖMR V/3, Nr. 184. Zu den Diskussionen im Reichsrat siehe BlaAs, Italienische Frage, 201f. Der Antrag des Finanzausschusses wurde nach kurzer Debatte angenommen: Prot. Reichsrat, AH 1861/62, 3051-3055 (130. Sitzung v. 16. Juni 1862). Die Angelegenheit wurde zwar im MR I v. 10. November 1862/3, ÖMR V/3, Nr. 229 diskutiert, aber nicht gelöst.

516 Kriegsministerium an Außenminister Rechberg v. 13. Jänner und v. 31. Jänner 1862, KA, KM-Präs., Z 170, 368 und 861/1862. Über die finanziellen Details und den notwendigen Nachtragskredit siehe ebd., Z 2139 und 3903.

517 MR v. 13. Dezember 1862/2, ÖMR V/5, Nr. 298 und MR v. 17. Oktober 1863/4, ÖMR V/7, Nr. 406. Zur Auflösung der Brigade siehe v.a. Anm. 7. Zur Aufnahme in die Finanzwache Vortrag des Finanzministers v. 1. Oktober 1863, Ah.E. v. 3. November 1863, HHStA, Kab.Kanzlei, KZ 3141. 